\title{
Electrophoretic behaviour of human urinary amylase
}

\author{
C. FRANZINI \\ From the Clinical Laboratory of the City Hospital of S. Antonio Abate, \\ Gallarate, Italy
}

SYNOPSIS A saccharogenic method is described for estimating amylase activity in human urine. Results accord with those reported elsewhere except that in this study the peak in the beta zone is o a new finding. Comparison between normal and pathological urines suggests that the amylase $\dot{\circ}$ activity of the beta peak is not of pancreatic origin.

Serum iso-amylases have been widely studied in animals and man by means of several fractionating methods, including electrophoresis, DEAE-cellulose chromatography, and gel filtration.

Results of the early work, in which amyloclastic methods were used for the determination of enzymic activity, can be criticized on the basis of the effect of proteins on the starch-iodine colour development (Wilding, 1963; Searcy, Ujihira, Hayashi, and Berk, 1964). When due allowance is made for this 'protein effect', serum amylase activity, studied by paper electrophoresis, seems to be mainly confined to the gamma-globulin zone, although some activity is found also in other electrophoretic fractions (Kawaguchi, Berk, Ujihira, Zeineh, and Searcy, 1963; Searcy et al., 1964). From Sephadex columns serum amylase is eluted as a single peak (Wilding, 1963). Although urinary amylase too is reported to be eluted as a single peak from Sephadex columns and to show a single peak in the gamma-globulin zone on paper electrophoresis (Wilding, 1963), no detailed information is available on the human urinary amylase isoenzymes.

Optimal conditions for a sensitive amylase assay by a saccharogenic technique were developed in our laboratory, and we applied our method to the investigation of the electrophoretic behaviour of human urinary amylase.

\section{METHODS}

Twenty-four-hour urine specimens were obtained from healthy young men and from a subject with acute pancreatitis (the diagnosis was confirmed at laparotomy). Urines were concentrated by vacuum ultrafiltration first by means of an LKB ultrafilter and afterwards by a slightly modified apparatus similar to that described by Bocci (1964); a $500-800$ fold concentration was atReceived for publication 16 February 1965. tained. Aliquots, each of $50 \mu \mathrm{l}$., of the concentrated $\mathcal{S}$ urine (in duplicate) were applied to strips of Whatmano $3 \mathrm{MM}$ paper and electrophoresis was carried out in vero- $\frac{\mathbb{D}}{D}$ nal buffer at $p$ H 8.6 under standard conditions at room temperature. At the end of the migration period (10-12 hours) one strip was oven-dried and stained with amido- $\rightarrow$ black. The other was cut into $0.5 \mathrm{~cm}$. segments and each $\mathscr{\sigma}$ segment was eluted in $3 \mathrm{ml}$. of $0.02 \mathrm{M}$ phosphate buffer .7 at $p \mathrm{H}$ 7. Optical densities of the eluates were read at $280 \mathrm{~m} \mu$ in a Beckman DU spectrophotometer against a suitable blank.

Amylase determinations were performed by incubating $0.2 \mathrm{ml}$. of each eluate with $0.2 \mathrm{ml}$. of a $2 \%$ starch $\frac{0}{8}$ solution (soluble starch, Merck) in $0.15 \mathrm{M}$ sodium chlor- $\varrho$ ide in $0.02 \mathrm{M}$ phosphate buffer at $p \mathrm{H} 7$ for $30 \mathrm{~min}$. at $\overrightarrow{\bar{O}}$ $37^{\circ} \mathrm{C}$. At the end of the incubation period $3 \mathrm{ml}$. of a 3 phenylhydrazine reagent (Stroes and Zondag, 1963) was added and the tubes were centrifuged. The clear supernatants were decanted and heated in a boiling water bath for $30 \mathrm{~min}$. and, after cooling, the yellow colour which $\frac{\rho}{0}$ developed due to osazone formation was read at $395 \mathrm{~m} \mu$ in б a Beckman DU spectrophotometer against a suitable blank. The spectrophotometric readings were referred to $⿱ 乛$ a calibration chart prepared with maltose and the results 3 were calculated as $\mu \mathrm{M}$ maltose liberated per millilitre per hour. The samples to be analysed, when necessary, were diluted with the phosphate buffer so that enzyme activities were always on the linear part of the relation between enzyme concentration and colour development. $N$

The stained strips were scanned in an automatic re-os cording densitometer (Chromoscan, Joyce, Loebl \& Co.). N

\section{RESULTS}

Typical results for a normal urine and for pancreatitis urine are shown in Figure 1. Amylase activities (in $\mu \mathrm{M}$ maltose $/ \mathrm{ml} . / \mathrm{hr} .$, logarithmic scale) and protein concentrations (optical densities at $280 \mathrm{~m} \mu, \overline{0}$ linear scale) are plotted against tube number (dis- $\overrightarrow{\mathbb{D}}$ tance from the point of application). Clearly in both $\frac{\rho}{\Phi}$ normal and in pancreatitis urine most of the amylase $\varrho$ 


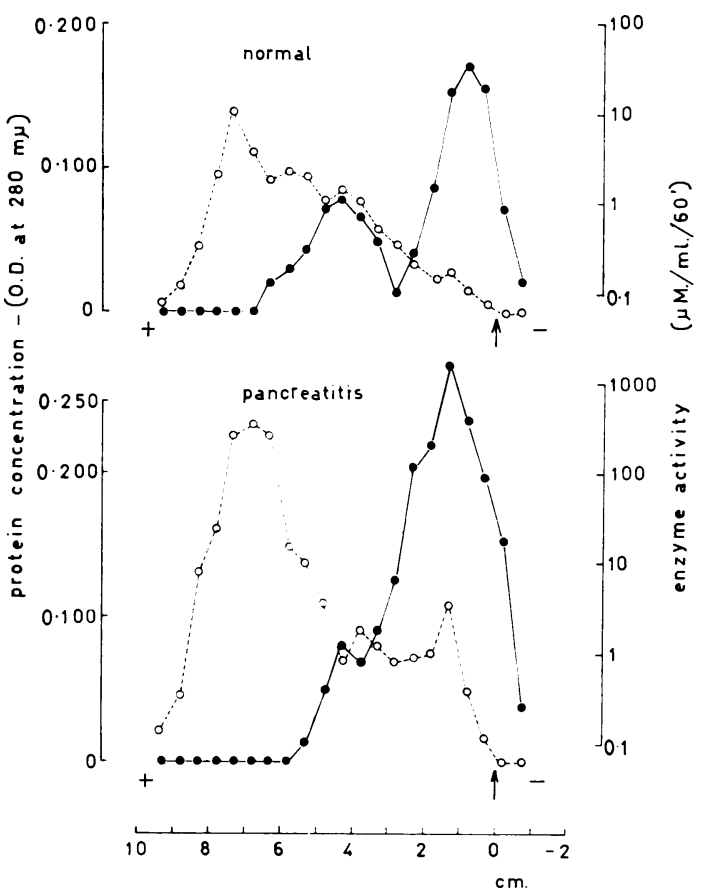

FIG. 1. Distribution of amylase activity (O-O) and proteins $\left(\bigcirc-\bigcirc^{-}\right)$in the electrophoretic strips from normal and pancreatitis urine. On the abscissa the distance from the points of application is marked by arrows.

activity is recovered in the gamma-globulin zone, while a minor peak is found in the beta-globulin zone. In the albumin zone, despite a raised protein concentration, there was no amylase activity. Recovery of the material applied to the strip was 80$110 \%$ as protein (absorption at $280 \mathrm{~m} \mu$ ) and $50-80 \%$ as enzymic activity.

The enzymic activity in the beta peak was $1-2 \%$ of the total activity recovered in normal urines and less than $0.1 \%$ in pancreatitis urine. However, total activities of the beta peaks from normal and pancreatitis urines were of the same size, the great increase of amylase activity of pancreatitis urine being confined to the gamma peak.

The specific activity, calculated as $\mu \mathrm{M}$ per $\mathrm{ml}$. per hour, per O.D. at $280 \mathrm{~m} \mu$, was 2,410 for the gamma peak of normal urine and 11,300 for the corresponding peak of the pancreatitis urine.

The densitometric tracings from the stained strips could be roughly superimposed on the corresponding graphs of optical density at $280 \mathrm{~m} \mu$.

\section{DISCUSSION}

The evidence reported here, demonstrating that the main peak of amylase activity in human urine is in the gamma globulin electrophoretic zone, is in agreement with the data reported by others (Wilding, 1963) and with the electrophoretic mobility of the main peak of human serum amylase (Dreiling, Janowitz, and Josephberg, 1963; Kawaguchi et al., 1963; Searcy et al., 1964). The peak in the beta zone has not been previously described in urine.

Special attention was paid to the fractions which displayed no amylase activity, since enzymic activity associated with all human serum protein fractions, particularly with albumin, has been reported in work employing a saccharogenic technique (Kawaguchi et al., 1963; Searcy et al., 1964). In the present experiments an amylase activity was recorded as $O$ when the optical density of the test versus the blank was $<0 \cdot 005$. Even when the eluates from the albumin peak were incubated for two hours instead of for 30 minutes the optical density was $<0.005$. For such an incubation an amylase activity less than $1 / 1,000$ of the main peak of a normal urine would have been clearly visible (O.D. $>0.010)$. It should be noted that, with our conditions of assay, colour development (sugar liberation) was linear with the time of incubation up to two hours with both the enzymes from the two described electrophoretic peaks. Therefore there was no amylase activity of the albumin zone as estimated by the criterion described.

Comparison between normal and pathological urine suggests that the amylase activity of the beta peak is not of pancreatic origin. This is consistent with the finding that the addition of pancreatic juice to human serum increases the amylase activity in the gamma globulin zone (Dreiling et al., 1963).

The high specific activity of the gamma peak from pancreatitis urine suggests the possibility that the homogeneous protein peak in the gamma zone exhibited by pancreatitis urine is due to increased elimination of amylase.

We are indebted to Professor I. Mingazzini for the material from the pathological case, and the technical collaboration of Miss E. Ercoli is gratefully aknowledged.

\section{REFERENCES}

Bocci, V. (1964). Science Tools, 11, 7.

Dreiling, D. A., Janowitz, H. D., and Josephberg, L. J. (1963). Ann. intern. Med., 58, 235.

Kawaguchi, M., Berk, J. E., Ujihira, I., Zeineh, R., and Searcy, R. L. (1963). Clin. Chem., 9, 496.

Searcy, R. L., Ujihira, I., Hayashi, S., and Berk, J. E. (1964). Clin. chim. Acta, 9, 505.

Stroes, J. A. P., and Zondag, H. A. (1963). Ibid., 8, 152.

Wilding, P. (1963). Ibid., 8, 918. 